\title{
Income and health behaviours. Evidence from monitoring surveys among Finnish adults
}

\author{
M Laaksonen, R Prättälä, V Helasoja, A Uutela, E Lahelma
}

J Epidemiol Community Health 2003;57:711-717

See end of article for authors' affiliations

Correspondence to Dr M Laaksonen, PO Box 41, University of Helsinki, Helsinki, Finland; mikko.t.laaksonen@helsinki.fi

Accepted for publication 14 January 2003

\begin{abstract}
Study objective: To examine the associations of individual and household income with various health behaviours, before and after adjusting for educational attainment and occupational social class.

Design and Setting: Data from 19982 respondents to nationwide health behaviour surveys from 1993 to 1999 (response rate 70\%) were linked with socioeconomic information from population registers.

Measurements: The income measures were total individual income liable to taxation and household's monthly disposable income. Health behaviours included smoking, alcohol use, leisure time physical activity, use of vegetables, use of saturated fat on bread, and being overweight.

Main results: In men, smoking and infrequent vegetable use were more common among those with lower individual and household income. However, adjusting for education and occupational class removed most of the differences. Use of saturated fat on bread increased with decreasing individual income, before and after the adjustments. In women, smoking, infrequent vegetable use and being overweight were more common among those with lower income, but the differences by both income measures were largely removed by the adjustments. Women with higher income more often also were high alcohol users and had less physical activity, in particular when income was measured by the respondents' individual income.

Conclusions: Adjusting for education and occupation largely removed income differences in health behaviours, but for some behaviours some independent effect remained. The results suggest that income does not only reflect the available material resources, but works as a general socioeconomic indicator that is associated with health behaviours in much the same way as other socioeconomic indicators.
\end{abstract}

S cioeconomic position has consistently shown clear differences by almost any health outcome examined. ${ }^{12}$ To varying degrees, these differences are reproduced for different forms of health behaviour. Health behaviours thus constitute a set of potential factors that may contribute to the inverse association between socioeconomic position and health..$^{3-5}$ To narrow socioeconomic differences in health and to promote favourable behaviours throughout the whole population more information about the distribution of health behaviours by socioeconomic divisions is therefore needed. ${ }^{6}$

One way of advancing our understanding of the socioeconomic differences in health behaviours is to examine these differences using alternative indicators of socioeconomic position. The most important indicators of socioeconomic position include educational attainment, occupational social class, and income..$^{7-10}$ These indicators are interrelated: higher education is likely to allow a better position at the labour market, which in turn offers higher income. Therefore, these indicators have often been treated as interchangeable measures of socioeconomic position. However, these indicators also represent different aspects of socioeconomic position, and their influence on health behaviours may therefore follow different pathways. For example, education provides knowledge, skills, and competencies that may be important to avoiding or abandoning harmful behaviours. Occupational life involves human relations and networks that may influence health behaviours. Income more clearly than the other indicators of socioeconomic position relates to material wellbeing and financial resources that may contribute to health behaviours through consumption. Thus, each indicator is likely to reflect both the common impacts of a general ranking in society as well as particular impacts related to the specific nature of each socioeconomic indicator.
In research on health behaviours education has been the most widely used indicator of socioeconomic position, as it has been found to most clearly discriminate health behaviours and related biological risk factors. ${ }^{811}{ }^{12}$ However, other indicators may provide additional information on the associations between socioeconomic position and health behaviours. In recent research on socioeconomic differences in morbidity and mortality increasing attention has been paid to income and material living conditions, ${ }^{13}{ }^{14}$ but the associations between income and health behaviours have so far been scarcely examined. ${ }^{15-18}$ Most commonly income is regarded to reflect material resources, but it indicates broader socioeconomic aspects as well. The lack of material resources may affect health behaviours through financial restrictions that prevent healthy choices, although it is clear that all healthy choices do not require money. Especially household income can be taken to indicate people's spending power, ${ }^{192}$ while individual income also reflects status or prestige, autonomy, and power of decision.

In this paper we examine the associations between income and a range of health behaviours. Nationwide Finnish health behaviour surveys with register linkage for socioeconomic information provide a unique opportunity to study these associations. The analyses are made using both individual and household income and separately for men and women. As income is partly determined by educational background and occupational status, which may be more important to health behaviours than income as such, the effect of income may be confounded by these other socioeconomic indicators. Therefore, we examine the associations between income and health behaviours before and after adjusting for these other socioeconomic indicators. The aim is to explore the associations between individual and household income and various 
forms of health behaviour, and to test whether the observed associations between income and health behaviours are removed when education and social class are taken into account.

\section{METHODS}

The data derive from a series of nationwide surveys conducted within the Health Behaviour among Finnish Adult Population project by the National Public Health Institute. ${ }^{21}$ Annually mailed surveys to a random sample of 5000 Finns aged 15-64 years reached overall response rates of about $70 \%$. The response rate was somewhat lower than average among men, in younger age groups, and among the less educated. This study used health behaviour data from the surveys conducted in 1993-1999. As studying socioeconomic differences is most feasible among the working aged, the analyses were restricted to 25-64 year old respondents who usually have completed their education but who have not yet passed the general retirement age. Overall, 9324 men and 10658 women were included in this study.

Health behaviours examined include smoking, alcohol use, physical activity, use of vegetables, saturated fat use on bread, and being overweight. Smoking status was determined on the basis of several questions concerning smoking history and the time of the last smoking occasion. Alcohol use was estimated as a sum of the reported weekly consumption of beer, long drinks (mixture of gin and grapefruit soda), wine, and spirits. Cider was added to the list in 1997, as its consumption was low in the beginning of the 1990s but increased remarkably during the decade as more brands became available. ${ }^{22}$ The portions of these alcoholic beverages that contained 12-14 grams of pure alcohol were then summed together. Physical activity was assessed on a six point scale describing the weekly frequency of moderately strenuous leisuretime physical activity. Frequency of fresh vegetable use was asked by a question with four response alternatives, and saturated fat use on bread was based on a question with six categories of spread with varying degree of saturated and unsaturated fat. Being overweight was described in terms of body mass index (BMI), calculated from self reported height and weight.

The health behaviours were dichotomised using the following cut off points for unhealthy end of the behaviours: daily smoking, drinking more than 15 (men) or 8 (women) portions of alcohol per week, having physical activity less than four times per week, eating fresh vegetables less often than daily, using mainly butter or mixture of butter and oil on bread, and having a BMI higher than 27. All cut off points could not be determined merely on the basis of the assumed health effects and current recommendations of engaging in these behaviours. Especially the cut off point for high alcohol use was comparatively low. Although heavier drinkers may underestimate their consumption more than moderate drinkers, we believe that those who reported highest drinking broadly represent the heaviest drinkers among the respondents. Cut off points for unhealthy behaviours are always somewhat arbitrary and there are no strict limits where the health risk associated with each behaviour would suddenly appear or sharply increase. However, we cannot totally exclude the alternative that somewhat different findings would have emerged if another cut off points had been used.

The personal identification code was used to link socioeconomic information at the individual level from population registers to the survey data. Information was available on two income measures, educational attainment and occupational social class. The income measures were total individual income liable to taxation and household's monthly disposable income (including transfers and excluding taxes). Information on income was based mainly on the nationally covering taxation register and complemented by the registers of the Social Insurance Institution and the Central Pension Security
Institute. ${ }^{23}$ The registers contain information of all income sources that are subject to state taxation, including wages and salaries, entrepreneurial income, property income, pensions, and welfare benefits. As men and women differ in their average income level, the two income measures were divided into quintiles separately for men and women. Each income quintile thus included slightly less than 2000 men and slightly more than 2000 women. Educational attainment was derived from the Register of Completed Education and Degrees by Statistics Finland, and classified to basic education (corresponding approximately to less that 10 years of education), secondary education (10-12 years), and university degree ( 13 years or more) ${ }^{23}$ Information on income and education were linked to the survey data for the corresponding years, but occupational social class was available only from the 1995 population census, where the classification of social class is compiled the on the basis of occupation, industrial status, industry and employer sector, and main type of activity. ${ }^{23}$ Occupational social class was categorised according to the standard occupational classification of Statistics Finland, including separate categories for the early retired and the unemployed. The respondents were classified according to their own occupation, but housewives were placed into the same category with their husbands.

We first present the age standardised prevalence of the unhealthy behaviours by income quintiles. The age standardisation was made by the direct method in five year age groups. Logistic regression analysis was then used to examine the effect of other socioeconomic indicators on the associations between income and health behaviours. The analysis was made in two phases: firstly, the associations of individual or household income with health behaviours were examined adjusting for age and study year. Then, education and occupational social class were added to the model to see how these other socioeconomic indicators affect the associations between income and health behaviours. As information on the household consumption units was not directly available, the composition of the household was taken into account by adjusting all analyses for marital status and having dependent children in the family. The results from the logistic regression analyses are presented as odds ratios and their $95 \%$ confidence intervals. The highest income quintile was used as the reference category $(\mathrm{OR}=1.00)$.

\section{RESULTS}

Table 1 shows the socioeconomic and demographic characteristics of the study population. Almost half of both men and women had a secondary education and one fifth had a university degree. More men than women were blue collar workers, whereas in women lower white collar employees formed proportionately larger group than in men. The groups of the early retired and the unemployed were also quite large in this sample. Intermediate age groups were slightly larger than the extreme groups. Three of four respondents were married or cohabiting, and slightly less than half of them had dependent children.

Among men, smoking, infrequent use of vegetables and high saturated fat use were more common among those with lower income, while high alcohol use, physical inactivity, and being overweight were quite evenly distributed across the income quintiles (table 2). Individual and household income showed very similar distributions, with only saturated fat use showing a slightly steeper gradient by household income. Among women, smoking, infrequent use of vegetables and having a high BMI were inversely associated with income. The gradient for smoking was somewhat steeper by household income, and that for overweight by individual income. High alcohol use was more common and saturated fat use less common among women with higher individual income. However, this was not found for household income. Physical inactivity was slightly more common in lower individual and household income groups. 


\begin{tabular}{|c|c|c|c|c|}
\hline \multirow{2}{*}{$\begin{array}{l}\text { Demographic and socioeconomic } \\
\text { characteristics }\end{array}$} & \multicolumn{2}{|l|}{ Men } & \multicolumn{2}{|c|}{ Women } \\
\hline & $\mathrm{N}$ & $\%$ & $\mathrm{~N}$ & $\%$ \\
\hline \multicolumn{5}{|l|}{ Education } \\
\hline Basic education & 3034 & 33 & 3136 & \\
\hline Secondary education & 4382 & 47 & 5041 & 47 \\
\hline University degree & 1908 & 21 & 2481 & \\
\hline \multicolumn{5}{|l|}{ Occupational social class } \\
\hline Employers and self employed workers & 1066 & 11 & 779 & 7 \\
\hline Upper white collar employees & 1369 & 15 & 1332 & 13 \\
\hline Lower white collar employees & 1301 & 14 & 3640 & \\
\hline Blue collar workers & 2474 & 27 & 1658 & \\
\hline Early retired & 1246 & 13 & 1182 & \\
\hline Unemployed & 1376 & 15 & 1356 & 13 \\
\hline Other/unknown & 492 & 5 & 711 & 7 \\
\hline \multicolumn{5}{|l|}{ Age $(y)$} \\
\hline $25-29$ & 997 & 11 & 1252 & 12 \\
\hline $30-34$ & 1162 & 13 & 1325 & 12 \\
\hline & 1174 & 13 & 1446 & \\
\hline $40-44$ & 1298 & 14 & 1493 & 1 \\
\hline $45-49$ & 1405 & 15 & 1611 & 15 \\
\hline $50-54$ & 1224 & 13 & 1396 & \\
\hline $55-59$ & 1079 & 12 & 1132 & 11 \\
\hline $60-64$ & 985 & 11 & 1003 & \\
\hline \multicolumn{5}{|l|}{ Marital status } \\
\hline Married or cohabiting & 6883 & 74 & 7809 & 74 \\
\hline Single & 1641 & 18 & 1365 & 13 \\
\hline Divorced or separated & 685 & 7 & 1072 & 10 \\
\hline Widowed & 83 & 1 & 369 & \\
\hline \multicolumn{5}{|l|}{ Having children in the family } \\
\hline No & 5517 & 59 & 5858 & 55 \\
\hline Yes & 3807 & 41 & 4800 & \\
\hline
\end{tabular}

Results from logistic regression analyses are presented in tables 3 and 4 . In men, smoking was clearly more common in the lower individual and household income groups (table 3 ). The inverse gradient for individual income seemed to be slightly stronger than that for household income. Adjusting for education and occupational social class weakened the associations but a clear inverse gradient remained. For alcohol use, some indication of a curvilinear association was found: those in the intermediate income categories tended to drink slightly less than those in the extreme categories. This association seemed slightly stronger by household income than by individual income. Adjustments for the other socioeconomic indicators had no effects at all. Physical inactivity was less common among those with lower individual or household income, but these differences attenuated and did not reach statistical significance after the adjustments. Infrequent vegetable use was more prevalent in the lower income groups. Adjusting for education and social class removed the gradient by individual income but only halved it by household income. Those with low individual income more often used saturated fat on bread but no differences were seen by household income. The effects of the adjustments were small. Being overweight was not associated with household income in men.

Also in women smoking was more common in the lower income groups (table 4), but this association was less clear than in men. Adjusting for education and occupational social class removed the association by individual income, but by household income a clear inverse gradient remained. Those with higher income more often were high alcohol users, more clearly when measured by individual income than by household income. As in men, adjustment for the other socioeconomic indicators had no effects on the income differences in alcohol use. Physical inactivity was less common among those with lower individual income, but by household income the differences between income categories were small, and they were removed entirely after the adjustments. Infrequent vegetable use was clearly associated with lower individual and household income. These associations remained clear after the adjustments. Saturated fat use was slightly more common in lower income groups, but this association was removed after the adjustments. Unlike men, women in lower income groups were more often overweight. This association was more pronounced by individual income than by household income. Adjusting for education and social class removed most of the association.

\section{DISCUSSION}

This study used extensive health behaviour data with register linkage to examine how individual and household income are associated with various forms of unhealthy behaviour. Health behaviour information came from surveys on large nationwide random samples of the general Finnish population with reasonable response rate. Socioeconomic information from reliable register based sources was available to practically all respondents. The measures of income included all significant sources of current income, transfers, and welfare benefits but excluded savings and inherited property. As occupational social class for all respondents was based on the 1995 population census, this linkage was made partly backward and partly forward. The deviation from the year of the health behaviour

Table 2 Prevalence of unhealthy behaviours by individual and household income quintiles $(\%)$, adjusted for age

\begin{tabular}{|c|c|c|c|c|c|c|c|c|c|c|}
\hline & \multicolumn{5}{|c|}{ Individual income quintile } & \multicolumn{5}{|c|}{ Household income quintile } \\
\hline & Highest & 2nd & $3 \mathrm{rd}$ & 4 th & Lowest & Highest & 2 nd & $3 r d$ & 4th & Lowest \\
\hline \multicolumn{11}{|l|}{ Men } \\
\hline Smoking & 22 & 26 & 31 & 38 & 41 & 21 & 26 & 33 & 36 & 41 \\
\hline High alcohol use & 23 & 18 & 18 & 20 & 24 & 22 & 20 & 18 & 19 & 24 \\
\hline Physical inactivity & 77 & 76 & 75 & 73 & 70 & 78 & 76 & 74 & 72 & 71 \\
\hline Low vegetable use & 61 & 67 & 73 & 78 & 81 & 62 & 67 & 74 & 78 & 78 \\
\hline Saturated fat use & 24 & 24 & 27 & 29 & 28 & 20 & 23 & 26 & 30 & 31 \\
\hline High BMI & 32 & 34 & 36 & 32 & 32 & 31 & 34 & 33 & 35 & 33 \\
\hline \multicolumn{11}{|l|}{ Women } \\
\hline Smoking & 15 & 17 & 20 & 22 & 22 & 13 & 16 & 19 & 23 & 27 \\
\hline High alcohol use & 18 & 14 & 12 & 12 & 12 & 15 & 14 & 13 & 13 & 15 \\
\hline Physical inactivity & 78 & 75 & 74 & 68 & 69 & 74 & 76 & 73 & 73 & 69 \\
\hline Low vegetable use & 45 & 54 & 59 & 64 & 63 & 47 & 55 & 60 & 61 & 62 \\
\hline Saturated fat use & 21 & 22 & 23 & 27 & 25 & 24 & 25 & 23 & 21 & 24 \\
\hline High BMI & 19 & 23 & 26 & 28 & 31 & 21 & 24 & 26 & 29 & 25 \\
\hline
\end{tabular}


Table 3 Unhealthy behaviours by individual and household income, ${ }^{*}$ odds ratios and their $95 \%$ confidence intervals before and after adjusting for other socioeconomic indicators, men

\begin{tabular}{|c|c|c|c|c|}
\hline & \multicolumn{2}{|l|}{ Individual income } & \multicolumn{2}{|l|}{ Household income } \\
\hline & Unadjusted & Adjusted & Unadjusted & Adjusted \\
\hline \multicolumn{5}{|l|}{ Smoking } \\
\hline Highest income quintile & 1.00 & 1.00 & 1.00 & 1.00 \\
\hline 2nd income quintile & 1.34 (1.15 to 1.56$)$ & $0.96(0.82$ to 1.13$)$ & $1.27(1.10$ to 1.48$)$ & $1.00(0.86$ to 1.18$)$ \\
\hline 3rd income quintile & 1.86 (1.60 to 2.17$)$ & $1.18(1.00$ to 1.40$)$ & 1.58 (1.36 to 1.83$)$ & 1.11 (0.95 to 1.30$)$ \\
\hline 4th income quintile & 2.11 (1.81 to 2.46$)$ & $1.26(1.06$ to 1.50$)$ & 2.06 (1.78 to 2.40$)$ & 1.42 (1.21 to 1.67$)$ \\
\hline Lowest income quintile & $2.56(2.19$ to 2.98$)$ & 1.52 (1.27 to 1.83$)$ & 2.09 (1.78 to 2.45$)$ & $1.36(1.14$ to 1.61$)$ \\
\hline \multicolumn{5}{|l|}{ High alcohol use } \\
\hline Highest income quintile & 1.00 & 1.00 & 1.00 & 1.00 \\
\hline 2nd income quintile & $0.83(0.71$ to 0.97$)$ & $0.87(0.74$ to 1.03$)$ & $0.72(0.61$ to 0.84$)$ & $0.74(0.63$ to 0.87$)$ \\
\hline 3rd income quintile & 0.74 (0.63 to 0.87$)$ & $0.80(0.67$ to 0.96$)$ & $0.69(0.59$ to 0.82$)$ & 0.72 (0.61 to 0.86$)$ \\
\hline 4th income quintile & $0.78(0.66$ to 0.92$)$ & 0.83 (0.69 to 1.01$)$ & $0.76 \quad(0.64$ to 0.89$)$ & $0.78(0.66$ to 0.93$)$ \\
\hline Lowest income quintile & $0.96(0.82$ to 1.13$)$ & 1.01 (0.83 to 1.24$)$ & $0.87(0.73$ to 1.02$)$ & $0.89(0.74$ to 1.07$)$ \\
\hline \multicolumn{5}{|l|}{ Physical inactivity } \\
\hline Highest income quintile & 1.00 & 1.00 & 1.00 & 1.00 \\
\hline 2 nd income quintile & 0.89 (0.76 to 1.04$)$ & 0.97 (0.82 to 1.14$)$ & $0.97(0.83$ to 1.13$)$ & $1.05(0.90$ to 1.23$)$ \\
\hline 3rd income quintile & 0.81 (0.69 to 0.94$)$ & 0.91 (0.77 to 1.08$)$ & $0.93(0.80$ to 1.09$)$ & $1.06(0.90$ to 1.25$)$ \\
\hline 4th income quintile & $0.71 \quad(0.61$ to 0.83$)$ & 0.85 (0.71 to 1.02$)$ & $0.84(0.72$ to 0.98$)$ & 0.99 (0.84 to 1.17$)$ \\
\hline Lowest income quintile & 0.76 (0.64 to 0.89$)$ & $0.92(0.76$ to 1.11$)$ & $0.83(0.70$ to 0.98$)$ & $1.02(0.86$ to 1.22$)$ \\
\hline \multicolumn{5}{|l|}{ Low vegetable use } \\
\hline Highest income quintile & 1.00 & 1.00 & 1.00 & 1.00 \\
\hline 2nd income quintile & 1.32 (1.15 to 1.51$)$ & 0.94 (0.81 to 1.09 ) & 1.37 (1.20 to 1.57$)$ & 1.08 (0.94 to 1.25$)$ \\
\hline 3rd income quintile & 1.82 (1.58 to 2.10$)$ & $1.12(0.96$ to 1.32$)$ & 1.76 (1.53 to 2.02 ) & 1.25 (1.08 to 1.45$)$ \\
\hline 4th income quintile & 2.21 (1.90 to 2.57$)$ & 1.30 (1.09 to 1.55$)$ & 2.24 (1.93 to 2.61$)$ & 1.58 (1.35 to 1.86$)$ \\
\hline Lowest income quintile & 1.98 (1.70 to 2.31$)$ & 1.17 (0.97 to 1.40$)$ & 2.27 (1.93 to 2.68 ) & 1.54 (1.29 to 1.85$)$ \\
\hline \multicolumn{5}{|l|}{ Saturated fat use } \\
\hline Highest income quintile & 1.00 & 1.00 & 1.00 & 1.00 \\
\hline 2nd income quintile & 1.23 (1.05 to 1.43$)$ & 1.20 (1.01 to 1.41$)$ & $1.03(0.89$ to 1.20$)$ & $0.97(0.83$ to 1.14$)$ \\
\hline 3rd income quintile & 1.44 (1.23 to 1.68$)$ & 1.37 (1.15 to 1.62$)$ & 1.26 (1.09 to 1.46$)$ & $1.15(0.98$ to 1.34$)$ \\
\hline 4th income quintile & 1.77 (1.52 to 2.07$)$ & $1.68(1.40$ to 2.00$)$ & 1.32 (1.13 to 1.54$)$ & 1.18 (1.01 to 1.39 ) \\
\hline Lowest income quintile & 1.77 (1.51 to 2.08$)$ & 1.66 (1.38 to 2.00$)$ & 1.19 (1.01 to 1.40$)$ & 1.04 (0.87 to 1.24$)$ \\
\hline \multicolumn{5}{|l|}{ High BMI } \\
\hline Highest income quintile & 1.00 & 1.00 & 1.00 & 1.00 \\
\hline 2nd income quintile & $1.16(1.01$ to 1.34$)$ & $1.03(0.89$ to 1.20$)$ & 1.12 (0.98 to 1.29$)$ & $1.02(0.89$ to 1.18$)$ \\
\hline 3rd income quintile & $1.10(0.95$ to 1.26$)$ & 0.92 (0.78 to 1.07$)$ & 1.20 (1.04 to 1.38 ) & $1.05(0.91$ to 1.21$)$ \\
\hline 4th income quintile & $1.22(1.05$ to 1.40$)$ & $0.98(0.83$ to 1.15$)$ & 1.03 (0.89 to 1.19 ) & $0.88(0.76$ to 1.03$)$ \\
\hline Lowest income quintile & $1.12(0.97$ to 1.30$)$ & 0.90 (0.75 to 1.07$)$ & $1.00(0.86$ to 1.17$)$ & $0.84(0.71$ to 1.00$)$ \\
\hline
\end{tabular}

survey was small in both directions, and the overall design of this study can be considered cross sectional. Therefore, strict causal judgements cannot be made. In health inequalities research reverse causation is widely discussed, but in recent reviews its effect has been considered rather small. ${ }^{24} 25$ Furthermore, the possible reverse causation between low socioeconomic position and unhealthy behaviours is not as straightforward as with poor health. As a direct link from health behaviours to a person's socioeconomic position is unlikely, it is plausible that the order of the association runs mainly to the opposite direction.

The data on health behaviours were based on self reports. People may tend to report their behaviours more healthy that they really are, but it is unlikely that the reliability of self reports would largely differ from one socioeconomic group to another. Therefore, we do not expect reporting bias to substantially affect our findings on health behaviours across the income categories. Another possible source of bias relates to non-response in the health behaviour survey. Attempts to reach the non-respondents to compare them with the respondents have not yet been made with the current data, but other studies suggest that the non-respondents may differ from the respondents in their health behaviour. ${ }^{26}{ }^{27}$ In our data slight differences in the response activity were observed by sociodemographic background characteristics. Differences between income categories might also be affected if the nonrespondents differed in their health behaviour from one income category to the next. Such differences would be likely to underestimate rather than upwardly bias the differences between income groups, but differences in non-response between the income categories would need to be fairly large to change the results.

The results showed marked differences between income and some of the health behaviours while others were quite evenly distributed. Smoking and infrequent vegetable use were more common among men and women with a lower income. In women, being overweight was more common in lower income groups. In contrast, women with higher income more often were high alcohol users and had less leisuretime physical activity, in particular when the measure of individual income was used. In men, those with low individual income more often used saturated fat on bread.

After adjusting for education and occupational social class many of the associations observed were attenuated. For smoking and infrequent use of vegetables, as well as overweight in women, the adjustments removed most of the income differences. Yet, even after adjusting for these additional socioeconomic indicators that presumably causally precede income, a slight income gradient remained. This suggests that income does have some "independent effect" on engaging these behaviours. Furthermore, in women, the associations of individual income with high alcohol use and low physical activity remained after the adjustments. Similarly, in men the association between individual income and saturated fat use was unaffected by the adjustments.

The results were largely similar for individual and household income. In women, the differences often tended to be slightly stronger for individual income. This may possibly reflect the control women have over their own personal earnings. In men no similar overall tendency was found, but saturated fat use showed a clear inverse gradient only by 
Table 4 Unhealthy behaviours by individual and household income, ${ }^{*}$ odds ratios, and their $95 \%$ confidence intervals before and after adjusting for other socioeconomic indicators, women

\begin{tabular}{|c|c|c|c|c|}
\hline & \multicolumn{2}{|l|}{ Individual income } & \multicolumn{2}{|l|}{ Household income } \\
\hline & Unadjusted & Adjusted & Unadjusted & Adjusted \\
\hline \multicolumn{5}{|l|}{ Smoking } \\
\hline Highest income quintile & 1.00 & 1.00 & 1.00 & 1.00 \\
\hline 2nd income quintile & 1.15 (0.97 to 1.35$)$ & $0.79(0.67$ to 0.95$)$ & 1.24 (1.05 to 1.46$)$ & 0.99 (0.84 to 1.18 ) \\
\hline 3rd income quintile & 1.50 (1.28 to 1.76$)$ & $0.91(0.76$ to 1.09$)$ & 1.48 (1.25 to 1.75$)$ & 1.13 (0.95 to 1.34$)$ \\
\hline 4th income quintile & 1.59 (1.35 to 1.87$)$ & $0.89(0.73$ to 1.07$)$ & 1.69 (1.42 to 2.00$)$ & 1.29 (1.08 to 1.54$)$ \\
\hline Lowest income quintile & 1.68 (1.42 to 1.98 ) & $0.92(0.75$ to 1.12 ) & 1.87 (1.56 to 2.24 ) & 1.30 (1.07 to 1.59 ) \\
\hline \multicolumn{5}{|l|}{ High alcohol use } \\
\hline Highest income quintile & 1.00 & 1.00 & 1.00 & 1.00 \\
\hline 2nd income quintile & $0.72(0.61$ to 0.85$)$ & $0.76(0.64$ to 0.90$)$ & $0.96(0.81$ to 1.13$)$ & $1.02(0.86$ to 1.21$)$ \\
\hline 3rd income quintile & $0.62(0.52$ to 0.73$)$ & 0.65 (0.54 to 0.79$)$ & $0.81 \quad(0.68$ to 0.96$)$ & 0.87 (0.73 to 1.05 ) \\
\hline 4th income quintile & $0.61(0.51$ to 0.73$)$ & $0.63(0.51$ to 0.77$)$ & $0.74(0.62$ to 0.90$)$ & 0.81 (0.67 to 0.98$)$ \\
\hline Lowest income quintile & $0.61 \quad(0.51$ to 0.74$)$ & $0.61(0.50$ to 0.76$)$ & $0.79(0.65$ to 0.97$)$ & 0.88 (0.71 to 1.09 ) \\
\hline \multicolumn{5}{|l|}{ Physical inactivity } \\
\hline Highest income quintile & 1.00 & 1.00 & 1.00 & 1.00 \\
\hline 2nd income quintile & 0.83 (0.72 to 0.96$)$ & $0.86(0.73$ to 1.00$)$ & 1.03 (0.90 to 1.19 ) & 1.09 (0.94 to 1.25 ) \\
\hline 3rd income quintile & 0.79 (0.68 to 0.91$)$ & $0.82(0.70$ to 0.96$)$ & $0.92(0.80$ to 1.06$)$ & 1.00 (0.86 to 1.15 ) \\
\hline 4th income quintile & $0.58(0.51$ to 0.67$)$ & 0.63 (0.54 to 0.74$)$ & 0.95 (0.82 to 1.10$)$ & $1.06(0.91$ to 1.23$)$ \\
\hline Lowest income quintile & 0.62 (0.54 to 0.72 ) & 0.66 (0.56 to 0.79 ) & 0.83 (0.71 to 0.96$)$ & 0.96 (0.81 to 1.14 ) \\
\hline \multicolumn{5}{|l|}{ Low vegetable use } \\
\hline Highest income quintile & 1.00 & 1.00 & 1.00 & 1.00 \\
\hline 2nd income quintile & 1.44 (1.27 to 1.62 ) & 1.14 (1.00 to 1.30$)$ & 1.44 (1.27 to 1.62$)$ & 1.22 (1.08 to 1.39$)$ \\
\hline 3rd income quintile & 1.80 (1.59 to 2.03 ) & 1.33 (1.16 to 1.52 ) & 1.71 (1.51 to 1.94$)$ & 1.39 (1.22 to 1.59 ) \\
\hline 4th income quintile & 2.16 (1.90 to 2.46 ) & 1.57 (1.36 to 1.82 ) & 1.75 (1.54 to 2.00$)$ & 1.41 (1.23 to 1.61$)$ \\
\hline Lowest income quintile & 2.14 (1.88 to 2.43 ) & 1.55 (1.33 to 1.81$)$ & 1.91 (1.66 to 2.21$)$ & 1.42 (1.22 to 1.66$)$ \\
\hline \multicolumn{5}{|l|}{ Saturated fat use } \\
\hline Highest income quintile & 1.00 & 1.00 & 1.00 & 1.00 \\
\hline 2nd income quintile & 1.06 (0.92 to 1.23 ) & $1.06(0.91$ to 1.24$)$ & 1.02 (0.89 to 1.17 ) & 1.00 (0.86 to 1.15$)$ \\
\hline 3rd income quintile & 1.09 (0.94 to 1.27$)$ & $1.06(0.90$ to 1.25$)$ & 0.97 (0.84 to 1.12 ) & 0.92 (0.79 to 1.07 ) \\
\hline 4th income quintile & 1.37 (1.19 to 1.59 ) & 1.28 (1.08 to 1.51$)$ & 0.86 (0.74 to 1.00$)$ & 0.80 (0.68 to 0.93 ) \\
\hline Lowest income quintile & 1.26 (1.09 to 1.46$)$ & $1.10(0.92$ to 1.31$)$ & 1.15 (0.98 to 1.35 ) & $1.00(0.84$ to 1.19$)$ \\
\hline \multicolumn{5}{|l|}{ High BMI } \\
\hline Highest income quintile & 1.00 & 1.00 & 1.00 & 1.00 \\
\hline 2nd income quintile & 1.28 (1.10 to 1.49$)$ & $1.10(0.94$ to 1.29$)$ & 1.14 (0.98 to 1.32$)$ & 1.02 (0.88 to 1.19 ) \\
\hline 3rd income quintile & 1.46 (1.25 to 1.69 ) & $1.16(0.99$ to 1.37$)$ & 1.34 (1.15 to 1.55$)$ & 1.14 (0.98 to 1.33 ) \\
\hline 4th income quintile & 1.72 (1.48 to 2.00$)$ & 1.25 (1.05 to 1.49 ) & 1.74 (1.50 to 2.02 ) & 1.43 (1.22 to 1.67$)$ \\
\hline Lowest income quintile & 1.91 (1.64 to 2.22$)$ & 1.36 (1.14 to 1.62$)$ & 1.60 (1.36 to 1.89$)$ & 1.21 (1.01 to 1.44$)$ \\
\hline
\end{tabular}

individual income. When the measure of household income was used, the results were more alike for men and women than when using individual income. This finding was expected, as household income is likely to be a better indicator of material wellbeing than individual income, especially for women. ${ }^{19}$ This is true also in Finland, where women hold full time jobs almost as often as men. However, as women generally have lower earnings than men, using household income as the income measure is likely to equalise the true disposable income between men and women. In our study only being overweight showed clearly different results for men and women by the two income measures. By individual income there was a gender difference also in alcohol use, smoking, and saturated fat use.

Few previous studies have examined income differences in health behaviours. Arinen et al have reported income differences in health behaviours among Finnish adults. ${ }^{18}$ Their results, based on the gross household disposable income per consumption unit after adjusting for age and gender, correspond to our findings as regards to alcohol use and overweight. However, in our study the inverse gradient for smoking was clearly steeper than what they observed. Also, unlike them, we found a modest decrease in physical activity by increasing income.

There exist a couple of studies that have used income as one measure of socioeconomic position in examining differences in an index of unhealthy behaviours. ${ }^{15}{ }^{16}$ Pomerleau et al have specifically examined differences in health behaviours by household income as well as other socioeconomic indicators among Canadians. ${ }^{17}$ Smoking showed an inverse income gradient, adjusting for gender, age, and marital status. When education, receiving family benefits, and occupational prestige were controlled for, this gradient was attenuated but it did not disappear entirely. Fat use showed no differences by income. Heavy alcohol use showed a positive association with income that remained after adjustments, and low physical activity an inverse association which attenuated and lost statistical significance after adjusting for additional socioeconomic indicators.

Compared with differences in health behaviours by other main indicators of socioeconomic position, our results with income are broadly compatible. ${ }^{21} 2829$ Smoking has generally shown an inverse gradient with any measure of socioeconomic position, so that especially those with the highest socioeconomic position smoke less often than the others. Those in the higher socioeconomic positions generally drink more frequently and more on average than those in lower socioeconomic positions, although problem drinking may be more common in the lower socioeconomic positions. Infrequent use of vegetables and high saturated fat use are generally more prevalent in lower socioeconomic positions. For some reason that remains unexplained, we found an inverse income gradient in fat use only by individual income in men. In physical activity socioeconomic differences have usually been small. Therefore, a steep inverse income gradient in physical inactivity in our study is somewhat unexpected. Our finding of the clear inverse socioeconomic gradient in being overweight in women, but not so much in men, corresponds to studies that measured socioeconomic position with income, education, or occupational class. ${ }^{30} 31$ 
Among the various socioeconomic indicators income is the one that can be regarded as best reflecting people's material resources. The primary link between material resources and health behaviours is that lack of money may limit the possibilities to engage in some healthy behaviours. As noted before, smoking is one example of a behaviour for which this link does not seem to apply, because non-smoking is the cheapest as well as the healthiest choice. ${ }^{32}$ Another potential explanation suggested for the inverse association between socioeconomic position and smoking, which is related especially to the material aspects of socioeconomic position, is that people might smoke to compensate for unfavourable socioeconomic conditions, such as low income. ${ }^{32-34}$ Yet, in our study the association between smoking and income was gradual, suggesting that not only poverty or adverse material circumstances lie behind this association. The effect of income should especially emerge after the other socioeconomic indicators are taken into account. The finding that even after the adjustments those with lower income smoke more often suggests that, along with spending power, income indicates also something else that cannot be fully captured by education or occupational class.

Our findings are also important to the prevention of smoking. Pricing policy has been regarded as among the most efficient means to curb smoking, and especially those with lower income are considered susceptible to price increases. ${ }^{35-37}$ Our finding that smoking is more common in the lower income groups, independently of other socioeconomic indicators, would not seem to support this economic aspect of smoking prevention. However, pricing policy has been sparingly used in Finland, where the price of tobacco products has followed the general consumer price index. ${ }^{38}{ }^{39}$ It seems that at least the current cigarette prices do not prevent smoking among those with the lowest income.

The results of our study suggest that, with respect to health behaviours, income does not only reflect available material resources but also works as a general socioeconomic indicator that is associated with health behaviours in much the same way as other socioeconomic indicators. This conclusion can be drawn from our results on six health behaviours, although smoking is most revealing in this respect. Income differences in health behaviours were largely similar to differences by other socioeconomic indicators in previous studies. ${ }^{21} 28-31$ Adjusting for education and occupation explained a large part of income differences in health behaviours, but some independent effect remained for some of the behaviours. Infrequent vegetable use was consistently associated with lower income in both genders, and narrowing of socioeconomic differences might be seen if the price of vegetables could be decreased. However, in general income differences in health behaviours seem not to be directly related to the financial costs of these behaviours. Income can be used as a general socioeconomic indicator, but like other socioeconomic indicators it may also reflect specific associations that cannot be found when other socioeconomic indicators are used instead.

\section{Authors' affiliations}

M Laaksonen, E Lahelma, University of Helsinki, Finland

R Prättälä, V Helasoja, A Uutela, National Public Health Institute, Finland

\section{REFERENCES}

1 Mackenbach JP, Kunst AE, Cavelaars AEJM, et al. Socio-economic inequalities in morbidity and mortality in western Europe. Lancet 1997;349: 1655-9.

2 Der G, Maclntyre S, Ford G, et al. The relationship of household income to a range of health measures in three age cohorts from the West of Scotland. Eur J Public Health 1999;9:271-7.
3 Macintyre S. The Black Report and beyond: what are the issues? Soc Sci Med 1997;44:723-45

4 Lantz PM, Lynch JW, House JS, et al. Socio-economic disparities in health change in a longitudinal study of US adults: the role of health-risk behaviors. Soc Sci Med 2001:53:29-40.

5 Sacker A, Bartley M, Firth D, et al. Dimensions of social inequality in the health of women in England: occupational, material and behavioural pathways. Soc Sci Med 2001;52:763-81.

6 Mackenbach JP, Bakker M, Sihto M, et al. Strategies to reduce socio-economic inequalities in health. In: Mackenbach JP, Bakker M, eds. Reducing inequalities in health: a European perspective. London: Routledge, 2002:25-49.

7 Dahl E. Social inequalities in ill-health: the significance of occupational status, education and income - results from a Norwegian survey. Sociology of Health and IIIness 1994; 16:644-67.

8 Backlund E, Sorlie PD, Johnson NJ. A comparison of the relationships of education and income with mortality: the national longitudinal mortality study. Soc Sci Med 1999;49:1373-84.

9 Miech RA, Hauser RM. Socio-economic status and health at midlife: a comparison of educational attainment with occupation based indicators. Ann Epidemiol 2001;11:75-84.

10 Lynch J, Kaplan G. Socioeconomic position. In: Berkman LF, Kawachi I, eds. Social epidemiology. New York: Oxford University Press, 2000:13-35

11 Winkleby MA, Jatulis DE, Frank E, et al. Socio-economic position and health: how education, income, and occupation contribute to risk factors for cardiovascular disease. Am J Public Health 1992;82:816-20.

12 Mirowsky J, Ross C. Education, personal control, lifestyle and health. A human capital hypothesis. Research on Aging 1998;20:415-49.

13 Lynch JW, Davey Smith G, Kaplan GA, et al. Income inequality and mortality: importance to health of individual income, psychosocial environment, or material conditions. BM 2000;320:1200-4.

14 Wagstaff A, van Doorslaer E. Income inequality and health: What does the literature tell us? Annu Rev Public Health 2000;21:543-67.

15 Luoto R, Pekkanen J, Uutela A, et al. Cardiovascular risks and socio-economic status: differences between men and women in Finland. J Epidemiol Community Health 1994:48:348-54

16 Pill R, Peters TJ, Robling MR. Social class and preventive health behaviour: a British example. J Epidemiol Community Health 1995;49:28-32.

17 Pomerleau J, Pederson LL, Ostbye T, et al. Health behaviours and socio-economic position in Ontario, Canada. Eur J Epidemiol 1997; 13:613-22.

18 Arinen S, Häkkinen U, Klaukka T, et al. Health and the use of health services in Finland: main findings of the Finnish health care survey 1995/96 and changes from 1987. Health Care 1998:5. Helsinki: STAKES, 1998

19 Rahkonen O, Arber S, Lahelma E, et al. Understanding income inequalities in health among men and women in Britain and Finland. Int Health Serv 2000;30:27-47.

20 Benzeval M, Judge K, Shouls S. Understanding the relationship between income and health: how much can be gleaned from cross-sectional data. Social Policy and Administration 2001;35:376-96.

21 Helakorpi S, Patja K, Prättälä R, et al. Health behaviour and health among Finnish adult population, Spring 2001. Publications of the National Public Health Institute B16/2001. Helsinki: National Public Health Institute, 2001.

22 STAKES. Intoxicants statistical yearbook 1999. Alcohol and drugs. Social Security 1999:2. Helsinki: STAKES, 1999.

23 Central Statistical Office of Finland. Classification of socio-economic groups. Handbooks 17. Helsinki: Central Statistical Office of Finland, 1989.

24 Blane D, Davey Smith G, Bartley M. Social selection: what does it contribute to social class differences in health. Sociology of Health and Illness 1993; 15:1-15

25 Goldman N. Social inequalities in health: disentangling the underlying mechanisms. Ann N Y Acad Sci 2001;954:118-39.

26 Smith C, Nutbeam D. Assessing non-response bias: a case study from the 1985 Welsh Hearth Health Survey. Heath Education Research 1990;5:381-6.

27 Hill A, Roberts J, Ewings $P$, et al. Non-response bias in a lifestyle survey. J Public Health Med 1997; 19:203-7.

28 Lahelma $\mathbf{E}$, Rahkonen $\mathrm{O}$, Berg MA, et al. Changes in health status and health behaviour among Finnish adults 1978-1993. Scand J Work Environ Health 1997;23:85-90.

29 Aromaa A, Koskinen S, Huttunen J. Health in Finland. Helsinki: National Public Health Institute and Ministry of Social Affairs and Health, 1999.

30 Sarlio-Lähteenkorva S, Lahelma E. The association of body mass index with social and economic disadvantage in women and men. Int J Epidemiol 1999;28:445-9.

31 Lahti-Koski M, Vartiainen E, Männistö S, et al. Age, education and occupation as determinants of trends in body mass index in Finland from 1982 to 1997 . Int J Obes Relat Metab Disord 2000 24:1669-76.

32 Stronks K, van de Mheen HD, Looman CW, et al. Cultural, material, and psychosocial correlates of the socio-economic gradient in smoking behavior among adults. Prev Med 1997;26:754-66.

33 Davey Smith G, Blane D, Bartley M. Explanations for socio-economic differentials in mortality: evidence from Britain and elsewhere. Eur J Public Health 1994;4:131-44. 
34 Schrijvers CTM, Stronks K, van de Mheen HD, et al. Explaining educational differences in mortality: The role of behavioral and material factors. Am J Public Health 1999;89:535-40.

35 Pekurinen $\mathbf{M}$, Valtonen $\mathrm{H}$. Price, policy and consumption of tobacco: the Finnish experience. Soc Sci Med 1987; 25:875-81.

36 Townsend J, Roderick P, Cooper J. Cigarette smoking by socio-economic group, sex, and age: effects of price, income, and health publicity. BM 1994;309:923-7.
37 Chaloupka FJ, Cummings KM, Morley CP, et al. Tax, price and cigarette smoking: evidence from the tobacco documents and implications for tobacco company marketing strategies. Tobacco Control 2002;11 (suppl 1):162-72.

38 Leppo K, Vertio H. Smoking control in Finland: a case study in policy formulation and implementation. Health Promotion 1986;1:5-16.

39 Statistics Finland. Tobacco statistics 1997. Health 1998:1. Helsinki: Statistics Finland, 1998. 